\title{
Preliminary Study on Teaching Reformation of Organic Chemistry
}

\author{
Xiaojiao YU, Jian ZHANG, Xiyan TANG, Wenqin DAI, Jie ZHAO \& Binghua YAO \\ Department of Applied Chemistry, Xi'an University of Technology, Xi'an 710048, China
}

\begin{abstract}
Organic chemistry is a important and fundamental course. It has its own characteristics and special knowledge system. In order to raise teaching quality and improve student's ability to apply knowledge, and cultivate talents with innovation, the teaching methods and teaching content of organic chemistry has been studied. The teaching reformation has been obtaining fine effect.
\end{abstract}

KEYWORD: Organic chemistry; Teaching reformation; Preliminary study

\section{INTRODUCTION}

Nowadays, science and technology is growing at an unprecedented pace with the rapid development. Chemistry as one of the central subjects of natural science, its growth rate is even more alarming. The number of new compounds discovered by chemists from less than 2 million kinds in 50 years ago to now more than 2000 million, and every day it is increased with the nearly thousands of speed, of which more than $90 \%$ are organic compounds. Organic chemistry as one of the four basic courses, rich content, broad social application, rapid development, and because of the mutual penetration and cross development with biology, materials science, computer science and chemical subdiscipline, resulting in huge theoretical system of organic chemistry teaching content sharp contradiction with fewer teaching hours. Lectures difficult, learning difficulties, especially in the conditions of the credit system, the teacher is necessary to complete lesson plans, to ensure the quality of teaching, and to emphasize the quality training and innovation ability enhancing of students. The traditional teaching methods and outdated course content has been difficult to adapt to the needs of modern organic chemistry development. For this reason, many educators have been studied from different aspects [1-7]. according to our the professional characteristics, and discussed the following aspects of on organic chemistry teaching reformation.

2 CONSTANTLY UPDATED COURSE CONTENT TO ESTABLISH THE APPROPRIATE TEACHING SYSTEM WITH THE TEACHING PROCESS REQUIRES

After more than a century of change, the current organic chemistry textbooks forms a the basic model with functional groups as the main line, structural theory as commander, and integration of stereochemistry, kinetics, spectroscopy and molecular orbital theory. To the late 1990s, its content and structure have remained relatively stable. But different authors and their textbooks, there are many different on the aspects of scheduling system, the chapter sequence, choice of content, manner described and focuses etc. There are its own characteristics. On the basis of reading a lot of teaching materials of domestic and foreign, constantly updated our course content, and gradually form a teaching system suitable to our professional development.

\subsection{Constantly updated course content to suitable for the development chemistry subject}

In the teaching process, not only requires students to master the basics of organic chemistry, but also pay attention to the new emerging theory, new responses and methods of organic chemistry, timely reflect the frontiers of organic chemistry. Such as the solvent effect, neighboring group effect, photochemical, host-guest chemistry, organometallic compounds, asymmetric synthesis, solid phase synthesis etc., as well as recent years appeared in the field of organic chemistry C60 with the novel and great prospects etc. These contents can be processing, the original curriculum system as carrier, penetrate as an active ingredient, making the teaching content to keep up with the step of development of the subject, and more contemporary. In the classroom teaching, different knowledge should be treated differently, such as solvent effects and neighboring group effect should be deeply and thoroughly talk about, the organometallic compounds part can be properly introduced, enable students have a basic 
understanding of this. While touch the host-guest chemistry and solid phase chemistry in passing, no in-depth discussion. Properly handle the content in the classroom teaching can make the students understand the latest developments in organic chemistry, not only can improve the students' interest in learning, but also can provide cutting-edge information in aspects of further exploration and research for students.

\subsection{Not rigidly adhere to the existing system of teaching itselffor the sequential arrangement of the chapter}

On the chapters arrangement, we implement early start, dispersion the difficulties, gradual, progressive approach, while keeping the curriculum system for scientific, logical and systematic. For example the chapter of stereochemistry can be taught in front of the chapter of olefins, at the time of the beginning of teaching, guide students to discuss at deeper level, deepen of students' understanding of the product with the stereostructure, and improve the students' interest in learning.

\section{CONDUCT MULTIMEDIA TEACHING}

Organic chemistry has many features including content-rich, complexity of molecular structures, reaction types, numerous reaction equation, abstraction reaction mechanism and common stereo chemical problems etc. Combined with it involved a wide range, poor logical and systematic, students learn it feels difficult, abstract to difficult understand. At the time of teaching, teachers should not only teach basic traditional content, but also pay attention to strengthening the content of modern organic chemistry, achieve the basic organic chemical content to modernization and the modern organic chemistry content to foundation. But with the teaching reform, the teaching hours of organic chemistry is compressed. The contradiction between limited classroom capacities in teaching system and ballooning classroom content become increasingly prominent. Multimedia teaching can effectively solve this contradiction.

\subsection{Using multimedia technology to increase the amount of information and the capacity of the classroom}

In the traditional mode of teaching, teachers need to spend a lot of time on drawing the blackboard and graphics. The teacher has no enough time to introduce more new knowledge that reflect the academic frontiers. Using multimedia teaching can save the blackboard writing time and improve the efficiency of the classroom. So that teachers while strengthening the foundation of teaching, able to introduce some of the new trends and results in development of the subject, and some important chemists in the history of organic chemistry and representation of work. Thus information of classroom teaching are increased. The students' scientific quality and ability have improved.

\subsection{Breakthrough teaching difficult by multimedia technology}

In traditional teaching, the abstract chemical structure, stereoisomerism and chemical reaction process have been a learning difficulty. The multimedia courseware can show the abstract contents, such as molecular orbital overlap process, the geometric characteristics of $\sigma$ bond and $\pi$ bond, molecular structure, organic reactions course, molecular structure and conformation etc.. It utilize the image, intuitive screen or $3 \mathrm{D}$ animation to emerge in front of students. A simple and boring lecture becomes a lively and vivid colorful demonstration lessons. The teaching content becomes more concrete, vivid and image. The students' understanding and memory for knowledge have enhanced. The students' interest and enthusiasm for learning were stimulated. The classroom atmosphere was animated. These teaching difficult were solved.

\section{REFORM OF TEACHING METHODS TO IMPROVE TEACHING QUALITY}

At the process of teaching, students often reflect the needs to memory reaction equation and content too reactive and too complex. The students listened very clear on the class, the book can also be understand but have problems for homework. The main reason is that the students have not a clear understanding of the theory of organic structure. And this led to cannot establish the basic framework for the relationship between structure and properties. And the students cannot clear understanding of the laws of organic reactions, used to isolate understanding and application some knowledge, and not good at classification, summary and comparison. Causing knowledge points of students confused with each other. To this end, we use a variety of teaching methods combination, mobilize the enthusiasm of students, and improve teaching quality.

\subsection{Multimedia teaching and traditional teaching combination}

In the classroom, due to the different professional and different students' knowledge, there will be a lot of different problems. But multimedia courseware for classroom teaching is unchanged and with 
unpredictability. It is difficult to adjust teaching content at any time according to the actual situation of the students in the classroom. Thus, the teacher according to the students reflect the situation in the classroom teaching process, to appropriate use the traditional blackboard teaching at any time. It develop to the traditional teaching strengths of randomness, flexibility and interactivity. The quality of classroom teaching is improved.

\subsection{Using teaching aids for assisted teaching}

The nature of the organic compound is determined by the structure. The most of organic compounds are three-dimensional spatial structure. And many chemical reaction process and mechanism are related with the stereochemistry. Stereochemistry is not only the teaching focus but also the teaching difficult points. The static text and images is difficult to visually represent the three-dimensional structure of the molecule. The teacher in addition to make threedimensional structural model in courseware, and demonstrates teaching aids model for students. For example demonstrates different conformation and representation of ethane, n-butane and cyclohexane, and shows the cis and trans isomers and optical isomers configuration etc. for students. This will not only help students develop spatial imagination and improve student interest in learning, but also make it easier for students to understand and master the knowledge of stereochemistry.

\subsection{Strengthening exercises classes and after-school summary}

Class exercises is a complementary and supplementary form of teaching, Exercises class is not a simple to explain the problems arising from the operation, but the key to carry on the analysis, discussion and summary. The students enable to further understand and master the relevant knowledge. At the same time, we aimed at some problem of the students difficult to grasp in organic chemistry. After a certain stage in the teaching, by summing up, so that students knowledge from the perceptual to rational, from scattered to systematic, thus capturing the general rules and points.

\section{CONCLUSIONS}

In the implementation of the "student-centered, respect for individual differences, focusing on personality development," the advanced educational concepts, Organic chemistry teaching reform also needs to continue in-depth and in order to meet the demands of the times. Organic chemistry teaching should be more integrated into the society, liferelated knowledge. It strengthen the theory and practice ties, and enable students to better understand the social, more scientific understanding of the world to promote the development of society.

\section{ACKNOWLEDGMENTS}

This work was supported by the General Undergraduate Course Colleges and Universities Teaching Reform Project of Shaan Xi Provincial Government (Grant no. 13BZ26) \& the National Science Foundation of China (Grant no. 21276208)

\section{REFERENCES}

[1] S. Avargil, O. Herscovitz, Y.J. Dori. Challenges in the transition to large-scale reform in chemicaleducation. Thinking Skills and Creativity, 2013 (219):1-19.

[2] Peter J. Fensham, Alberto Bellocchi. Higher order thinking in chemistry curriculum and itsassessment. Thinking Skills and Creativity, 2013(208):1-15.

[3] Terry Platta, Vicki Roth, Jack A. Kampmeierc. Sustaining change in upper level courses: peer-led workshops in organic chemistry and biochemistry. Chemistry Education Research and Practice, 2008, 9(2):144-148.

[4] YU Shanhui. The Heuristic Approach of organic chemistry. Higher Education in Chemical Engineering, 2005, 20(5):810.

[5] Bongani, D. Bantwini. How teachers perceive the new curriculum reform: Lessons from a school district in the Eastern Cape Province, South Africa. International Journal of Educational Development, 2010 (30): 83-90.

[6] Hale Bayram, Arif Comek. Examining the relations between science attitudes, logical thinking ability, information literacy and academic achievement through internet assisted chemistry education. Procedia Social and Behavioral Sciences, 2009 (1):1526-1532.

[7] Kristina Klara, Ning Hou, Allison Lawman, and Li-Qiong Wang. Developing and implementing a collaborative teaching innovation in introductory chemistry from the perspective of an undergraduate student. Journal of Chemical Education, 2013, (90): 401-404. 